\title{
¿Por qué y cómo investigar las minorías religiosas?
}

\author{
Why and how to investigate the religious minorities?
}

\author{
Alberto Montes Martínez ${ }^{1}$ \\ albertomontesmaster@gmail.com
}

\begin{abstract}
Resumen
Después de todas las polémicas y críticas que ha habido durante el siglo XX sobre la religión, a estas alturas es difícil, si no imposible, encontrar personas que nieguen la vigencia social de la religión. Y esto sucede, no sólo entre la gente corriente, sino también entre las personas de ciencia, en general y, sobre todo, entre los científicos sociales.

En este artículo nos proponemos dos tareas complementarias. La primera es justificar por qué es relevante la investigación sobre el fenómeno genérico de la religión y sobre las religiones concretas y minoritarias existentes en sociedad española, y especialmente en Cantabria. Y la segunda tarea es hacer propuestas sobre el modo de investigar las minorías religiosas existentes en nuestro país, que tiene algunas peculiaridades.
\end{abstract}

\section{Palabras claves}

Investigación sobre la religión, minorías religiosas en Cantabria, vigencia del comportamiento religioso, metodología para la investigación de las minorías religiosas.

\begin{abstract}
After all the controversy and criticism that occurred during the twentieth century on Religion, at this point it is difficult, if not impossible, to find people who deny the social relevance of religion. And this happens not only among ordinary people, but also among people in science in general and especially among social scientists.

In this article, we propose two complementary tasks. The first is to justify why it is relevant the research on the generic phenomenon of religion and existing religious minority groups in Spanish society, especially in Cantabria. The second task is to make proposals on how to investigate existing religious minorities in our country, which has some peculiarities.
\end{abstract}

\section{Keywords}

Research on religion, religious minorities in Cantabria, research methodology of religious minorities, validity of religious behavior.

Forma sugerida de citar: Montes Martínez, Alberto (2015). ¿Por qué y cómo investigar las minorías religiosas? Universitas, XIII(23), pp. 125-141.

1 Doctorando en la Universidad de Granada (España). 


\section{Introducción}

$\mathrm{Al}$ intentar adentrarnos en la multitud y variedad de posiciones de la población española frente al fenómeno de la religión, nos encontramos con actitudes muy diversas. A veces próximas, a veces antagónicas. Al menos vamos a señalar algunas para iniciar este artículo.

Habrá quien manifieste su personal agnosticismo y quien confiese su ateísmo indiferente $\mathrm{o}$, en ocasiones, militante por diferentes razones filosóficas, políticas o personales. Habrá creyentes indocumentados sobre sus propias creencias e incapaces de explicar o dar cuenta de las mismas si son preguntados sobre ellas, especialmente sobre el por qué y para qué de sus creencias. Nos encontraremos, incluso, con creyentes, formalmente ortodoxos desde el punto de vista doctrinal de sus respectivas confesiones religiosas, de sus creencias y de su moral, pero desganados o despreocupados de sus propias prácticas religiosas. Pero pocas personas, por no decir ninguna, niegan esa vigencia social de la religión de la que pueden, incluso, estar ausentes de distintas maneras en su vida personal y social.

Las actitudes frente a las "otras religiones" son igualmente variadas y preocupantes. Hay musulmanes que expresamente se manifiestan radicalmente contrarios a otras religiones que no sean el Islam. El argumento es bien conocido en el mundo católico: "Si mi religión es la verdadera las demás religiones no islámicas carecen de legitimidad y de verdad", tanto en los países islámicos como en los no islámicos. La guerra santa sería la expresión más radical de esta posición. Hay católicos convencidos de su fe cristiana y firmes en sus creencias que respetan y se muestran tolerantes con las "otras religiones" y que incluso colaboran en actividades interreligiosas e interconfesionales, (como la Semana de Oración por la Unidad de los Cristianos), aunque también hay algunos intolerantes con las demás religiones. Y algo parecido sucede también con otras religiones minoritarias que reafirman sus creencias, pero se mantienen distantes de las demás confesiones religiosas. Con ligeras variantes, quizá esta última actitud sea la más frecuente: practicar la propia religión minoritaria, pero mantenerse al margen de las demás.

En este artículo nos proponemos dos tareas complementarias. Nuestra primera y principal preocupación es justificar por qué es relevante la investigación sobre el fenómeno genérico de la religión y sobre las religiones minoritarias existentes en nuestra propia sociedad española y, de modo especial, en Cantabria, entorno propio de nuestra investigación. La primera intención, por tanto, 
es justificar por qué es relevante la investigación sobre el fenómeno genérico de la religión y sobre las religiones concretas existentes en nuestra propia sociedad. Y la segunda tarea es hacer propuestas sobre el modo de investigar las minorías religiosas existentes en nuestro país (Montes y Martínez, 2011).

Vamos, pues, a describir a continuación ambas tareas, experimentadas ya en investigaciones anteriores.

\section{Por qué investigar sobre la religión y el pluralismo religioso}

Partimos de un hecho incontestable: ¿cuál es la diversidad cultural de España? Nuestro país está constituido por pueblos diversos y culturas distintas en aspectos muy diferentes que, además de tener una historia común y compartir muchos rasgos culturales, son diferentes en otros. En síntesis, podríamos decir que España es un Estado multicultural, resultado de tradiciones culturales diferentes que convergen en algunos aspectos.

$\mathrm{Y}$ esto que sucede a nivel nacional y que denominamos sociedad multicultural, se expresa tanto en espacios territoriales y culturales concretos como son las Comunidades Autónomas, y se manifiesta también en un ámbito básico de la cultura como es el de la religión, dado que esta forma parte de aquella. A ello han contribuido en los últimos veinte años dos fenómenos decisivos cuyas motivaciones conocemos: el turismo y las migraciones.

España es hoy una sociedad multicultural, que en el ámbito de la religión, puede definirse por el pluralismo religioso. De manera que podemos afirmar que España se caracteriza actualmente por un pluralismo religioso frágil, pero creciente, aun reconociendo la existencia de una mayoría católica. Estamos ya muy lejos de los tópicos repetidos por algunos hasta la saciedad de la "España católica". Por el contrario, vivimos, desde hace muchos años, en un proceso de transformación política, social, cultural y religiosa, entendiendo que la religión es parte de la cultura. Nos estamos refiriendo principalmente al periodo temporal que va desde la transición política hasta el momento presente.

Como han demostrado diferentes estudios recientes sobre las minorías religiosas en España, promovidos por la Fundación Pluralismo y Convivencia, que se citan a continuación, (Briones, R. (dir.), Tarrés, S., Salguero, O., Fernández, E., Macía, C. y Suárez, V. (2010); Buades Fuster, J. y Vidal Fernández, F. (2007); Díez de Velasco, F. (ed.), Verona, N., Rodríguez R., Contreras, V., 
Galván, A., García, A., García, A., Abu Tarbush, J. (2008); Estruch, J., Gómez i Segalá, J., Griera, Mª Iglesias, A. (2006); Gómez Bahillo, C. (coord.), Sanz Hernández, A., Del Olmo Vicén, N. y Franco de Espés Mantecón, C. (2009); Hernando de Larramendi, M. y García Ortiz, P. (2009); López García, B., Ramírez Fernández, A., Herrero Galiano, E., Said Kirhlani, Tello Weiss, M. (2007); Montes del Castillo, A. y Martínez Martínez, MJa. (2011); Ruiz Vieytez, E.J. (dir.) (2010), vivimos en un contexto social definido por la diversidad cultural en el que el pluralismo religiosos es una clara manifestación de aquella.

Esta es la primera respuesta a la pregunta que hemos formulado: ¿por qué investigar sobre la religión? La Religión y el pluralismo religioso forman parte de la sociedad española. Nosotros pretendemos describir en qué medida la sociedad cántabra coincide en esto con otras regiones del Estado español que ya han sido estudiadas. Lo que dicho de otra manera quiere decir que pretendemos, por un lado, describir los rasgos y características de las minorías religiosas en Cantabria, y por otro, señalar sus singularidades si las hubiere.

Pero lo primero de todo es justificar el estudio de la religión y de las minorías religiosas existentes en Cantabria, que es nuestro campo de investigación en esta ocasión. Se trata de responder a la pregunta que encabeza este epígrafe: ¿Por qué estudiar la religión y el pluralismo religioso?

Respecto a la primera tarea, adelantamos nuestra respuesta y es que la investigación de la religión es relevante, incluso en las sociedades seculares actuales, por varias razones fundamentales, que exponemos a continuación.

1. El estudio de la religión es relevante, en primer lugar, por la vigencia social de la religión, incluso en sociedades supuestamente secularizadas. No sólo en la historia pasada la Religión ha sido un fenómeno universal en las diferentes etapas históricas y en las diferentes sociedades, como atestigua la historia de la Antropología (Kottak, 1994), sino en el momento presente dominado por el pensamiento científico y secular (Collins, 2007). Es en este contexto, en medio del cual surge simultáneamente el pensamiento científico y el pensamiento simbólico, que han sido considerados como dos modos de operar la mente humana en el marco de la antropología estructural (Lèvi-Strauss, 1958 y 1962). Pensamiento científico y pensamiento simbólico no aparecen como dos formas antagónicas e irreductibles del pensamiento humano, sino como dos expresiones de la única mente humana.

2. El estudio de la religión es relevante, en segundo lugar, por el creciente pluralismo religioso existente en España, relacionado con el régimen de li- 
bertades, con el turismo y con los procesos migratorios de las últimas décadas. Ya anteriormente se han recogido las referencias bibliográficas más recientes.

Muchos creían que el régimen democrático surgido en España en la transición política y el sistema de libertades que construimos los españoles tendría, como consecuencia inmediata la crisis del catolicismo y su desaparición de la esfera pública, y la aniquilación de las minorías religiosas, tanto de las minorías antiguas e internas de España ligadas al protestantismo, como de las otras minorías procedentes del fenómeno migratorio y del turismo.

Pero las cosas no son tan sencillas. Incomprensiblemente y contra todo pronóstico, la práctica religiosa se mantiene, al menos, en los momentos básicos o centrales del ciclo vital (nacimiento, adolescencia-juventud, matrimonio, enfermedad y muerte) y, de modo especial, en la educación en valores morales. Y la presencia de inmigrantes de los últimos veinte años ha incrementado la práctica religiosa, tanto de formas religiosas ya existentes con anterioridad en España, ligadas al evangelismo principalmente, como de las nuevas religiones activadas por las migraciones, como por ejemplo el Islam.

3. El estudio de la religión es relevante, en tercer lugar, debido a las diversas funciones que las religiones cumplen en las sociedades actuales. Ya lo advirtió el filósofo y sociólogo alemán Jürgen Habermas (2006), amigo personal del Papa Joseph Ratzinger, posiblemente el pensador más lúcido y agudo del siglo XX europeo, cuando afirmó:

Las tradiciones religiosas están provistas de una fuerza especial para articular intuiciones morales, sobre todo en atención a las formas sensibles de la convivencia humana. Este potencial convierte al habla religiosa, cuando se trata de cuestiones políticas pertinentes, en un serio candidato para posibles contenidos de verdad, que pueden ser traducidos entonces desde el vocabulario de una comunidad religiosa determinada a un lenguaje universalmente accesible (2006: p. 139).

Estas diversas funciones que cumplen las diferentes religiones tienen que ver con las distintas actividades que realizan en la sociedad y se manifiestan claramente en ellas. Son las siguientes:

Unas son actividades estrictamente religiosas, producto de sus propios sistemas de creencias, de sus prácticas rituales o de su propia moral religiosa, que en la mayoría de las religiones tiene claras exigencias de solidaridad y ayuda a los necesitados. 
Otras son actividades asistenciales, exigencia natural de sus principios morales sociales a veces con sus propios fieles y a veces también con los ajenos, procedentes de otras religiones o no creyentes. Así sucede de modo ejemplar con la institución de Cáritas, obra social de la iglesia española, en la que la ayuda se centra en las necesidades de la persona independientemente de su adscripción a una o a otra religión o a ninguna. La filosofía latente en esta posición es que el necesitado debe ser ayudado por sí mismo, es decir, por sus carencias, independientemente de sus creencias o prácticas religiosas.

No tienen menor importancia las llamadas actividades educativas, principalmente relacionadas con el aprendizaje de los principios y normas de su propia religión a través de las sesiones de formación de cada confesión. Pero a veces también tienen que ver con aprendizajes ajenos a la propia religión y que son aprendizajes instrumentales para integrarse en nuestro país. Así sucede con el aprendizaje de la lengua española en el caso de los inmigrantes árabes en España; con el aprendizaje de los derechos y deberes ciudadanos para sentirse ciudadanos de pleno derecho, o algo tan simple como el conocimiento de las normas de tráfico.

Otras son actividades culturales dentro o fuera de sus espacios religiosos, cuando realizan concentraciones para expresar y mostrar aspectos básicos de sus creencias en espacios públicos, realizar rituales públicos en momentos o festividades fuertes de su religión o plantear reivindicaciones a las autoridades sobre sus exigencias laborales o de cualquier otro tipo.

No son menos importantes las actividades económicas y jurídicas o de asesoramiento jurídicos a sus miembros. En unas ocasiones son actividades formales de asesoría jurídica en problemas concretos. Otras veces son actividades informales de asesoría, producto del boca a boca, que se transmiten sobre cuestiones tan diversas como la ubicación de oficinas gubernamentales o de organizaciones no gubernamentales, información sobre búsqueda de empleo en una determinada población, derechos laborales, búsqueda de centros educativos para sus hijos o sobre centros sanitarios.

4. El estudio de la religión es relevante, también, debido a los conflictos potenciales que pueden tener lugar entre las diversas religiones. En los países de mayoría musulmana, por ejemplo, las "otras religiones" están prohibidas, con riesgo de cárcel, castigos corporales, e, incluso en algunos casos, con la pena de muerte para sus practicantes.

Queremos, en definitiva, estudiar las minorías religiosas porque la diversidad cultural y religiosa no es un terreno neutral, dominado por la convivencia 
pacífica y el respeto a las diferencias, sino que puede ser un terreno propicio a los conflictos interreligiosos o interculturales y a la aparición de distintas formas de exclusión. Ésta, la exclusión social, puede ser activada por los poderes públicos, como sucedió en los regímenes comunistas hasta hace bien poco, y por las mayorías religiosas dominantes en sociedades democráticas sobre las minorías. Pero puede ser también el resultado de complicados procesos de autoexclusión de las minorías que al no "ser" aceptadas en una determinada sociedad o no "sentirse" aceptadas en la vida social, optan por replegarse hacia sí mismas y alejarse de la comunidad humana en la que están implantadas.

Así que, en resumen, estos son los motivos o razones que justifican esta investigación: la religión existe; la diversidad cultural es un fenómeno característico de las sociedades actuales, y también de la sociedad cántabra; las religiones mayoritarias o minoritarias cumplen determinadas funciones sociales que es preciso analizar y describir en cada caso, pues entre las confesiones religiosas pueden tener lugar complejos procesos de exclusión o autoexclusión.

A nosotros nos interesa de forma especial la exclusión que padecen las minorías o que ellas mismas generan en la sociedad cántabra, en este caso. Pues el proceso de inclusión-exclusión no es sólo una práctica de las mayorías religiosas, sociales o políticas sobre las minorías, que es lo más frecuente, sino que puede ser también una práctica de las minorías en cualquier sociedad. Tradicionalmente el proceso de inclusión-exclusión social se ha entendido como una forma de agresión que los grupos sociales dominantes (religiosos, sociales, políticos, etc.) ejercen sobre las diferentes minorías. Pero el proceso de inclusiónexclusión social debe ser analizado también como una conducta de inserción social, integración, o por el contrario de separación, automarginación y distanciamiento de las minorías en relación a las distintas mayorías.

En el ámbito educativo tenemos constantemente evidencias de estos fenómenos de inclusión-exclusión social referidos a llegada de nuevos niños a un aula o grupo de iguales. Los niños de un determinado nivel integran, cada año, a los nuevos compañeros que vienen de otros centros o los rechazan. Y, al mismo tiempo, los niños que cambian de colegio a veces se integran en el nuevo grupo de iguales, o se retraen y no se integran en el grupo. No vamos a entrar aquí en la discusión sobre qué factores condicionan la inclusión y la exclusión, pero la evidencia es que ambos movimientos de aceptación y rechazo, de integración o distanciamiento, tienen lugar.

Conviene recordar que esta visión estricta y rígida de la religión en materia sexual no es exclusiva para los ciudadanos de los países islámicos, sino que en 
el caso de algunas prácticas su prohibición se extiende a ciudadanos extranjeros que por motivos de trabajo residen por ejemplo en Arabia Saudí. Conozco personalmente el caso de una pareja de españoles que se han visto obligados a casarse para poder residir y trabajar en este país. Casos similares podrían multiplicarse.

\section{Propuestas para la investigación de las minorías religiosas}

Una vez justificadas las razones y motivos que activan la investigación del fenómeno de la religión y de las minorías religiosas, vamos a proponer a continuación algunos aspectos básicos sobre el estudio de esas minorías religiosas en España y, más concretamente en la Comunidad Autónoma de Cantabria.

El estudio de las minorías, en cualquier país es fundamental, sobre todo, si éstas están sometidas a diferentes formas de discriminación y, en coherencia, plantean fuertes y justificadas exigencias al Estado. El estudio de las minorías religiosas es igualmente importante, si se quieren construir sociedades democráticas regidas por la libertad y la igualdad en las que la paz social sea el sustrato de la convivencia en el marco de los Derechos Humanos.

De acuerdo con lo expresado anteriormente, en este apartado pretendemos señalar algunas cuestiones básicas que son imprescindibles en el estudio de las minorías religiosas. No vamos a abordar cuestiones habituales en toda investigación social sobre las que hay múltiples manuales, y sobre las que nosotros mismos hemos escrito recientemente un breve modelo de utilidad para los que se inician en la investigación social (Montes del Castillo y Montes Martínez, 2014, p. 91).

En la investigación sobre las minorías religiosas en Cantabria se han utilizado cuatro instrumentos en el trabajo de campo: una ficha de identificación de las entidades religiosas minoritarias, y tres guías de entrevista. Una destinada a los responsables de las comunidades locales de culto, otra a los líderes o responsables regionales de las diferentes confesiones religiosas minoritarias; y una tercera guía a responsables técnicos o políticos de las Consejerías de la Comunidad Autónoma que consideramos relacionadas con el fenómeno a estudiar. Aquí vamos a describir únicamente la Guía de Entrevista utilizada con los responsables de cada comunidad local de Culto.

Vamos, pues, a describir a continuación las principales cuestiones de la Guía de Entrevista para responsables de las comunidades locales de culto, que es el principal instrumento de los que hemos utilizado en el trabajo de campo. 
En este apartado vamos a describir la Guía de Entrevistas a líderes religiosos de las comunidades locales de culto y a comentar el sentido y orientación de cada uno de sus apartados. La finalidad de esta operación es justificar cada uno de los apartados de la Guía y explicar el modo de proceder en su aplicación a los líderes religiosos locales.

El mismo título de la Guía ya requiere una explicación. Se trata de una Guía de Entrevista a líderes religiosos de las comunidades locales de culto. Es, pues, un instrumento para recoger datos sobre entidades religiosas minoritarias y asociaciones mediante la técnica de entrevista en toda la Comunidad Autónoma de Cantabria.

Es una Guía abierta en el sentido que tiene una serie de bloques temáticos y en cada uno de ellos una serie de preguntas concretas. Por tanto, no es un cuestionario cerrado con preguntas estandarizadas y fijas. Es una Guía para realizar entrevistas mediante una aplicación personal y directa a los destinatarios de la misma. No se ha utilizado el teléfono, ni se ha dejado la entrevista en el local de culto para que fuera respondida con posterioridad a la visita, ni se han empleado otras modalidades indirectas de recogida de datos. Los destinatarios de la entrevista son los líderes religiosos de cada comunidad local de culto. Y la finalidad de las entrevistas es obtener información sobre la temática indicada mediante el contacto directo con el entrevistado a través de una conversación en el mismo local de culto. Se trata, en definitiva, de una técnica cualitativa para la obtención de datos de forma directa.

La Guía comienza con una introducción que aclara el por qué y para qué de la realización de la entrevista. En ella se indica que la finalidad de esta es recoger datos sobre entidades religiosas minoritarias y asociaciones existentes en Cantabria. Se aclara que los destinatarios de las entrevistas son los responsables de las comunidades locales de culto y las asociaciones, y que nos estamos refiriendo con este término a la unidad más pequeña de una confesión religiosa. Dicho de otra manera, se entiende por comunidad local de culto la unidad más pequeña de una confesión religiosa (Iglesia, capilla, mezquita, sinagoga, lugar de oración o de culto) que existe en una localidad (Pedanía, pueblo, municipio, ciudad) o barrio de la misma. Estas comunidades locales de culto pueden o no estar vinculadas a una unidad superior denominada Federación o Unión, que las agrupa con la misma denominación o con otra diferente, o bien funcionar de manera independiente y autónoma sin tener esa vinculación.

Conviene aclarar que los datos que se solicitan, por tanto, son, en primer lugar, de las entidades religiosas minoritarias, y de cada una de sus comunidades locales de culto. En algunos casos, como en el del Islam, a veces, se les llama 
centros islámicos. La cuestión es que nos referimos a la unidad más pequeña de una confesión religiosa que existe en una localidad o barrio de la misma.

Algunos grupos religiosos antes de constituirse en entidades religiosas, pueden comenzar sus actividades creando una Asociación que, con el paso del tiempo, puede transformarse en entidad religiosa en el sentido que le da el Ministerio de Justicia. Así sucede con frecuencia en el caso del Islam. También puede suceder que una entidad religiosa tenga su propia asociación a través de la cual realiza actividades sociales, culturales o de otro orden.

Todas las preguntas de esta Guía se refieren a entidades religiosas y asociaciones, excepto la pregunta 12 y la pregunta 14, que se refieren al entrevistado. La Guía recoge también, como es lógico, datos básicos de identificación como los siguientes: nombre del entrevistado, fecha en que se realiza la entrevista, lugar y tiempo de duración y nombre del entrevistador. Veamos, pues, los distintos bloques temáticos de la Guía de Entrevistas.

Nombre de la Entidad Religiosa o Asociación: En el punto 1 se registra el nombre exacto de la Entidad Religiosa o de la Asociación, tanto si está registrada o no en el Ministerio de Justicia; tanto si está legalmente o no constituida. Si está registrada el nombre será el que figure en el Registro, si no está registrada el nombre será el que facilite el entrevistado. Este dato puede después contrastarse con el Registro del Ministerio de Justicia.

Confesión a la que pertenece: En el punto 2 se pide información sobre la confesión religiosa mayor a la que pertenece o a la que la entidad o asociación está vinculada. Se selecciona la que corresponda de acuerdo con el catálogo de confesiones facilitado por el Ministerio de Justicia. Según los casos, se puede recoger la denominación más general (Ej. musulmanes), o además la denominación más concreta (Ej. sunii), si el grupo se identifica con esa corriente islámica. En algunos casos, además de la denominación más general (Ej. evangéli$\cos )$, y de una denominación más concreta (Ej. pentecostal) se puede hacer una segunda concreción (Ej. Iglesia de Filadelfia).

Ubicación-identificación de la Entidad Religiosa: En el punto 3 también se solicitan datos como la provincia, localidad, municipio, dirección postal, teléfono, e-mail y web de cada comunidad local de culto, que permiten la ubicación e identificación en cada caso.

Tipo de Entidad: En el punto 4 se trata de dilucidar si el grupo entrevistado tiene ya la condición de entidad religiosa, como tal, o es una Asociación, que realiza tareas tanto culturales y sociales como religiosas. $\mathrm{Y}$ en ambos casos, si además posee un local de culto, o no. Disponer de un local, sea propio o alqui- 
lado, es fundamental para todas las confesiones, que no se consideran tranquilas hasta el momento de disponer de un local propio. Pudiera parecer ingenua esta aspiración, pero no lo es porque el local propio da estabilidad a la comunidad de los creyentes.

Creación-Historia: En el punto 5 se trata de hacer una breve cronología de los diferentes lugares de culto y de la historia del grupo. Conviene registrar la fecha en que comenzó a funcionar, es decir, la fecha de comienzo de las actividades, que posiblemente no coincidirá con la fecha de su constitución legal o de registro, que generalmente es posterior. No se pregunta aquí por la fecha en que se registró, que se pregunta después. En el caso de ser entidad religiosa o asociación y además lugar de culto, también se pregunta si es el primer lugar de culto o no, y si ha habido varios lugares de culto y por qué motivos ha tenido lugar esas variaciones. A veces estos cambios de local revelan conflictos con el entorno. Interesa también recoger brevemente la historia o evolución del grupo. Se trata de que nuestro entrevistado explique no la historia de la Confesión Religiosa a la que pertenece, por ejemplo la historia del Islam, ni tampoco la historia del Islam en la Comunidad de Cantabria, sino la historia de ese grupo religioso, es decir, de su comunidad local de culto. Cómo fueron sus comienzos y cuál ha sido su evolución desde el punto de vista de comunidad religiosa.

Miembros de la Entidad Religiosa o Asociación: En el punto 6 se registra el número total de fieles o miembros, tanto con asistencia regular como con asistencia ocasional, es decir, en algún momento o circunstancia especial. Esta distinción es muy importante, aunque somos conscientes de que quizá en algún caso no sea posible hacer esa precisión. Es importante a la hora de hacer una valoración global de cada confesión religiosa minoritaria en el contexto de España o de cada Comunidad Autónoma. En la investigación realizada en la Región de Murcia hemos comprobado que la asistencia de fieles musulmanes a las mezquitas, ni en los días de máxima presencia como por ejemplo en la Fiesta de Ramadán, no tiene nada que ver con la población musulmana existente realmente en la Región.

También se deberá registrar el número de miembros según nacionalidad, origen religioso, género o edad. Se trata de ver cómo se distribuye el total de miembros en cada una de esas cuatro variables en cada comunidad local de culto.

En los tres primeros casos, se presenta la pregunta en forma de dicotomía, y de porcentaje aproximado cuando es mixta.

En la primera categoría (Nacionalidad) se pregunta también por las nacionalidades o países de origen de los miembros. 
En la segunda categoría (Origen religioso) se pregunta por la religión de origen en el caso de los conversos. Este es un dato decisivo para aclarar la procedencia de los miembros del grupo.

En la tercera categoría (Género) se pregunta además sobre la existencia o no de prohibición de participación de las mujeres. Como se puede suponer, es una pregunta más orientada al Islam y las respuestas son sorprendentes.

En la cuarta categoría (Edad) sólo se pregunta el porcentaje aproximado según los diferentes rangos de edad.

Inscripción-Registro de la Entidad Religiosa: En el punto 7 se trata de recoger la situación de legalidad o no de la Entidad Religiosa o de la Asociación, mediante la pregunta sobre el Registro en el Ministerio de Justicia (Entidades Religiosas) o en el Registro de Comunidad Autónoma (Asociaciones). Interesa también el número de registro exacto y la fecha de inscripción (Día, mes, año) de acuerdo con la documentación que posean. Tanto en caso afirmativo como en caso negativo se pregunta especificar. Es una pregunta importante para tener una información de la magnitud del fenómeno, pues la no inscripción no sólo es perjudicial para la misma Entidad, porque esa situación impide el acceso a ayudas y subvenciones oficiales, sino también para la investigación porque distorsiona los resultados.

Federación: En el punto 8 se indaga sobre la pertenencia del grupo a una entidad mayor. Con mucha frecuencia las entidades religiosas, es decir, las comunidades locales de culto, además de pertenecer a una confesión religiosa (Ej. Islam) están vinculadas a una unidad mayor denominada Federación o Unión (Ej. UCI$\mathrm{DE})$. Si está federada conviene registrar el nombre de la federación según catálogo, debido a las variaciones que tienen lugar en cuanto a la vinculación de una comunidad local de culto a una u otra federación y que repercuten en cuestiones tan domésticas como subvenciones concedidas por el Gobierno, etc.

Actividades: En el punto 9 se pregunta por las Actividades que realizan las Minorías Religiosas, clasificadas en cinco categorías: Religiosas, Asistenciales, Educativas, Culturales y Económicas y Jurídicas. Las respuestas que se solicitan son siempre Sí/No. Cuando la respuesta es Sí a una actividad hay que consultar el Anexo de Actividades para obtener más información cualitativa de cada una de ellas. Estas preguntas referidas a las Actividades son fundamentales porque revelan la orientación más o menos religiosa, o la orientación más o menos social y política de las comunidades locales de culto. Ahora que la preocupación por la presencia del Islam en Europa resulta preocupante para los diferentes Gobiernos, ésta es una cuestión básica. 
En ese cuadro se pregunta por el nombre de la actividad, lugar en que se realiza (Centros públicos, sede social, equipamiento municipal, local privado, vía pública, etc.), si es programa propio (con fondos propios, personal propio, etc.) y breve descripción de en qué consiste tal Actividad. También es necesario preguntar si las actividades se realizan en entidades públicas y con fondos públicos, y si sus destinatarios son sólo los fieles propios o el público en general. Tenemos noticia de que en algunos casos se atiende sólo a los miembros de la propia Confesión, cosa que nos consta no sucede con Cáritas, donde se atiende al necesitado porque es necesitado, sin preguntar ni por su religión ni por sus preferencias políticas o morales.

Sobre las Actividades Religiosas conviene especificar cuáles son las Festividades principales que realizan y recoger en Anexo Celebraciones. Especificar el nombre de la celebración, cada cuánto tiempo se realiza y breve descripción del ritual que se realiza.

Sobre las Actividades Educativas además de señalar cuáles son, es especialmente importante aclarar si actúan en el sistema educativo español o si tienen colegio propio.

Sobre las Actividades Culturales, además de registrar cuáles son, conviene aclarar en cuanto a los medios de comunicación, si disponen de medios propios o actúan en medios ajenos, públicos o privados.

Sobre las Actividades Económicas y Jurídicas se pretende indagar sobre la implicación de la Entidad Religiosa o de la Asociación en actividades económicas, no del Entrevistado. Aunque si se obtiene este dato está bien y puede ser relevante.

Recursos (Subvención y/o Convenio): En el punto 10 se pretende investigar las fuentes de financiación de las actividades que se realizan, especificando si son recursos propios o recibidos del exterior, es decir, de otras entidades. Es muy importante detectar el apoyo de Arabia Saudí en el caso del Islam, y de potentes iglesias norteamericanas en el caso de los evangélicos y de otras Confesiones.

Si lo afirmado en el párrafo anterior se confirma, esto cuestiona el sistema de subvenciones promovido en su momento por el Gobierno de Rodríguez Zapatero desde la Fundación Pluralismo y Convivencia, y el victimismo de algunas minorías religiosas cuando critican al catolicismo. De cada subvención recibida conviene recoger datos concretos de las ayudas o subvenciones, para describir cada subvención con estas categorías: Título del Proyecto o actividad subvencionada, Año, Euros concedidos, Entidad Colaboradora (Gobierno de España, Gobierno de Cantabria, Municipios, Gobierno de otro país, otras insti- 
tuciones nacionales o extranjeras, particulares) y breve descripción de la actividad o proyecto subvencionado.

Inmueble: En el punto 11 se trata de profundizar un poco más en los recursos, indagando sobre el local o locales de que dispone. Es decir, de la sede social de la Entidad o Asociación y las fuentes de financiación. De nuevo también aquí, la fuente de financiación es importante.

Persona entrevistada: En el punto 12 se trata de obtener algunos datos básicos de la persona entrevistada. Se procurará que el entrevistado sea el responsable máximo del grupo de modo que en caso de necesidad pueda completar datos necesarios o aclarar algunos aspectos de las respuestas a la Guía de Entrevista.

Relaciones de la Entidad Religiosa con el entorno: En el punto 13 se pretende investigar sobre las relaciones de la Entidad Religiosa o Asociación con el mundo exterior que se especifica del siguiente modo: con otras entidades religiosas, incluida la Iglesia Católica, con instituciones públicas (Administraciones central, autonómica y municipal), con instituciones privadas (Empresas, fundaciones, $\mathrm{ONG}$, sindicatos, partidos políticos, etc.), y también con el entorno social próximo. Esto último es especialmente importante, tanto si son relaciones de colaboración como de conflicto. Conviene detallar con precisión, tanto en un caso como en otro, porque ésta es una de las claves, aunque no la única, de la integración o de la exclusión.

Opinión del entrevistado sobre cuestiones en debate: En el punto 14 se formulan varias preguntas de carácter ideológico, es decir, de opinión, referidas a la libertad religiosa, los convenios con el Gobierno en esa materia, la discriminación de su Entidad religiosa, los derechos humanos y el principio de reciprocidad aplicado a la libertad religiosa.

Sobre exclusión-inclusión social: En el punto 15 se trata de identificar normas de Gobierno central, autonómico o municipal y situaciones sociales que revelen exclusión social por razones de religión. Conviene tener en cuenta que la exclusión social es una conducta activa (hay individuos e instituciones que excluyen a otros individuos e instituciones o que se autoexcluyen) o una conducta pasiva (hay personas e instituciones que son excluidas o padecen la exclusión).

Se presentan cinco ámbitos preferentes en los que se puede detectar la exclusión social. Son estos: educación, sanidad, servicios sociales, justicia y trabajo. Se trata de identificar en cada caso las diferentes formas de exclusión y sus características. Además hay otros ámbitos en los que tiene lugar la exclusión, pero que resultan más sutiles y de difícil análisis (Vida comunitaria o ámbito de las relaciones sociales, etc.). 
También se formulan preguntas sobre visibilidad social del grupo religioso, agresiones del exterior en sus actividades, acceso a subvenciones, acciones en lugares públicas sólo o con otros grupos religiosos cedidos por instituciones públicas.

En todos los ámbitos de exclusión nombrados se indaga también sobre qué se ha considerado exclusión- inclusión.

No se trata sólo de identificar conductas de exclusión social o de inclusión sino de analizar las normas del Gobierno central, autonómico o municipal que revelen exclusión social por razones de religión. La exclusión social es una conducta activa (hay individuos e instituciones que excluyen a otros individuos e instituciones o que se autoexcluyen) o una conducta pasiva (hay personas e instituciones que son excluidas o padecen la exclusión).

$\mathrm{Y}$ esto puede suceder en los ámbitos señalados anteriormente: Hay cinco ámbitos preferentes en los que se puede detectar la exclusión social, aunque tenga rasgos diferentes. Y estos ámbitos preferenciales son: educación, sanidad, servicios sociales, justicia y trabajo. Además hay otros ámbitos en los que tiene lugar la exclusión pero que resultan más sutiles y de un análisis más complejo. Así sucede en la vida comunitaria o en el ámbito de las relaciones sociales.

Carencia y necesidades: En el punto 16 se pregunta por las carencias como comunidad religiosa (Edificio, cementerio, mobiliario, personal, etc.). Qué necesidades básicas tienen en este momento. Y se formulan tres preguntas definitivas como las siguientes: 1) ¿Cuáles son los objetivos prioritarios de su grupo religioso en este momento? 2) ¿Cuáles son las necesidades principales de su grupo religioso en la actualidad? 3) ¿Cuáles son las dificultades principales y las demandas a la sociedad española, a las instituciones y al Gobierno?

En este caso las preguntas se refiere a las carencias como comunidad religiosa en términos de edificio y locales, cementerio, mobiliario, personal, etc.

Por último en el punto 17 se registran algunos detalles significativos de la entrevista, tales como actitud favorable o no del entrevistado, sus comentarios, duración, personas presentes, opinión y comentarios sobre distintos aspectos de la investigación, etc. Y también registrar aquí las impresiones personales del investigador sobre el contenido de la misma: los temas principales, la interpretación intuitiva del investigador sobre los datos recogidos, las reclamaciones directas o indirectas de las minorías religiosas dirigidas al Gobierno y la sociedad española, en general, sobre el trato recibido en las instituciones, en las leyes y por parte de la población, etc. 
Para concluir solamente queremos indicar que en este artículo no hemos hecho más que un esbozo sobre dos cuestiones básicas en toda investigación: La primera cuestión es por qué realizar una investigación determinada. Nos parece que hemos argumentado adecuadamente sobre la necesidad de investigar el fenómeno de las minorías religiosas en Cantabria. La pequeña población de esta Comunidad Autónoma ha permitido realizar una investigación exhaustiva y a la vez manejable. La segunda cuestión ha sido las propuestas realizadas para la investigación de las minorías religiosas. Por nuestra experiencia en investigaciones anteriores sobre esta misma temática en la Región de Murcia, nos parece que hemos cubierto la mayor parte de las cuestiones relevantes.

Por último, no queremos terminar este artículo sin indicar una vez más que "la investigación es para la acción" y que, en consecuencia, todo proceso de "investigación de la realidad social" conduce a realizar "propuestas para la acción social" y mejorar la vida de la gente y las relaciones entre los diferentes grupos humanos. Ese es nuestro propósito con esta investigación sobre minorías religiosas en Cantabria (España): realizar propuestas para la intervención social.

\section{Bibliografía}

Briones, R. (dir.), Tarrés, S., Salguero, O., Fernández, E., Macía, C. y Suárez, V. (2010). ¿Y tu (de) quién eres? Minorías religiosas en Andalucía. Madrid: Fundación Pluralismo y Convivencia.

Buades Fuster, J. y Vidal Fernández, F. (2007). Minorias de lo mayor. Minorías religiosas en la Comunidad Valenciana. Madrid: Fundación Pluralismo y Convivencia.

Collins, F.S. (2007). Cómo habla Dios. La evidencia cientifica de la fe. México: Editorial Planeta.

Díez de Velasco, F. (ed.), Verona, N., Rodríguez R., Contreras, V., Galván, A., García, A., García, A., Abu Tarbush, J. (2008). Religiones entre continentes. Minorías religiosas en Canarias. Madrid: Fundación Pluralismo y Convivencia.

Estruch, J., Gómez i Segalá, J., Griera, Ma , Iglesias, A. (2006). Las otras religiones. Minorias religiosas en Cataluña. Madrid: Fundación Pluralismo y Convivencia.

Gómez Bahillo, C. (coord.), Sanz Hernández, A., Del Olmo Vicén, N. y Franco de Espés Mantecón, C. (2009), Construyendo redes. Minorías religiosas en Aragón. Madrid: Fundación Pluralismo y Convivencia.

Habermas, J. (2006) Entre naturalismo y religión. Barcelona: Paidos. 
Hernando de Larramendi, M. y García Ortiz, P. (2009). Religion.es. Minorías religiosas en Castilla-La Mancha. Madrid: Fundación Pluralismo y Convivencia.

Kottak, C.P. (1994). Antropología. Una exploración de la diversidad humana con temas de la cultura hispana. Madrid: McGraw-Hill.

Lèvi-Strauss, Cl. (1958/1970). Antropología estructural. Buenos Aires: Eudeba. (1962/1972). El pensamiento salvaje. México: F.C.E.

López García, B., Ramírez Fernández, A., Herrero Galiano, E., Said Kirhlani, Tello Weiss, M. (2007). Arraigados. Minorías religiosas en la Comunidad de Madrid. Madrid: Fundación Pluralismo y Convivencia.

Montes del Castillo, A. y Martínez Martínez, MaJ. (2011), Diversidad cultural y religión. Minorías religiosas en la Región de Murcia. Madrid: Fundación Pluralismo y Convivencia.

Montes del Castillo, A. y Montes Martínez, A. (2014). Guía para proyectos de investigación. Universitas. Revista de Ciencias Sociales y Humanas, 20, 91-126. Universidad Politécnica Salesiana.

Ruiz Vieytez, E.J. (dir.) (2010). Pluralidades latentes. Minorías religiosas en el País Vasco. Madrid: Fundación Pluralismo y Convivencia. 